\title{
Induction of Mitotic Abnormalities in Certain Genera of Tribe Vicieae by Paradichlorobenzene
}

\author{
L. M. Srivastava \\ Department of Botany, Ewing Christian College, Allahabad-3, India
}

Received July 23, 1965

Preliminary investigations of the author (Srivastava 1959) had revealed that paradichlorobenzene (PDB) caused various types of abnormalities in the chromosomal morphology of certain members of family Papilionaceae when pretreatment time was raised beyond 4 hours. It was, therefore, considered desirable to undertake detailed investigations dealing with the influence of this chemical on mitotic stages of three important genera of tribe Vicieae viz., Vicia, Pisum and Lathyrus.

\section{Materials and methods}

Vicia faba, V. narbonensis, V. hirsuta, Pisum arvense and Lathyrus sativus which are characterized by possession of large sized chromosomes were selected for the present studies. Seeds were germinated in small pots containing soil and organic manure in 50:50 ratio. At the time of maximum division the root tips were detached and immediately placed in saturated solution of $\mathrm{PDB}$. They were subsequently kept at $14 \mathrm{C}^{\circ}-18^{\circ} \mathrm{C}$ for $4-6$ hours and later squashed in aceto-orcein.

The magnification for all the photomicrographs (Mrs) was $\times 870$ except No. 12 for which it was $\times 2800$.

\section{Observations}

Following deviations from the normal mitosis were observed:

1) Shortening and contraction of the chromosomes far below their normal length

The first anomaly was that the chromosomes contracted far below their normal length and in proportion their diameter increased (Fig. 1). The primary and secondary constrictions were clearly visible but appeared as narrow gaps. When there was extreme condensation of the chromosomes, the constriction regions particularly the secondary constriction became invisible.

2) Precocious separation of the chromatids

At metaphase the two chromatids were observed to be separated on both the sides of the undivided centromere (Fig. 2) i.e., they lay side by side and were quite independent of one another except at the centromere where they remained attached. Sometimes the two chromatids extended out at right angles to one another and produced X-shaped bodies (Fig. 3).

3) Tetraploid cells

In some of the cells the centromere was found to be divided and the sister chromatids were seen completely separated out (Fig. 4). In all such 
cases complete separation of the chromatids had resulted in double the normal diploid number of chromosomes (Fig. 5).

4) Chromosome breaks

In few cases it was observed that PDB-treatment produced small acentric fragments (Fig. 6), while the two groups of anaphasic chromosomes had reached the poles, two such fragments (f) were found in the central part. In several preparations the large chromatic knob in the longest pair of chromosomes in Vicia faba was found to be separated from the main body of the chromosome (Fig. 7). In one of the rare cases in Vicia faba it was observed that breaks occurred in both the constricted regions, i.e., primary and secondary (Fig. 8). The chromatids had become completely separated from one another, each appearing as a whole chromosome, thereby the number of the chromosomes became double, i.e., 24. In addition the two longest pairs of chromosomes got broken into three parts (filled with India ink in Fig. 9), one consisted of the knob, and the other two were portions on either side of the primary constriction. The portions towards the secondary constriction side showed much greater contraction in length as compared with the other arm. The reconstruction of two such longest pairs of chromosomes had been done viz., I, II, III ; 1, 2, 3, i, ii, iii and a, b and c. Also some other chromosomes had formed fragments.

5) Chromosome bridges

In certain cases, cells in the early telophase stage showed chromosome bridges (Fig. 10). Ultimately these bridges broke up and the broken ends withdrew into the resting nuclei in which there was often found pear shaped projection to mark their position.

6) Failure of cell plate formation

In a few cases the spindle mechanism did not get destroyed and the two groups of anaphasic chromosomes moved to the poles. The cell plate, however, was not formed (Fig. 11). This ultimately resulted in a binucleate cell.

Besides these anomalies it was observed that the PDB-treatment also affected the size of the dividing cells. With the increase in the number of the chromosomes the cell size also increased. Another striking feature was that the spiral structure of the chromosomes could be easily made out at the mid-prophase, prometaphase and metaphase stages (Fig. 12).

\section{Discussion}

Carey and McDonough (1943) and Sharma and Bhattacharya (1956) made extensive studies on the influence of $\mathrm{PDB}$ in altering the chromosomal morphology of several plants but so far no such attempt was made on the plants under study. Though the studies dealing with the effect of antimitotic substances have attracted considerable attention of cytologists during the 

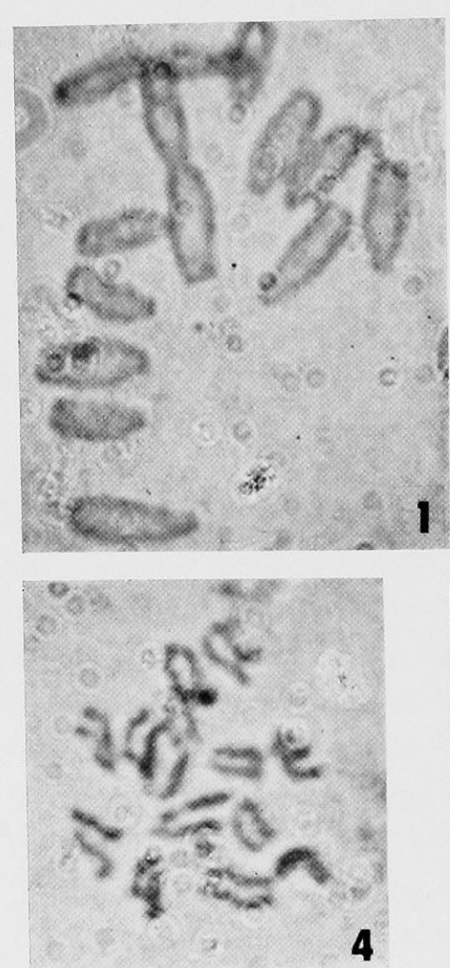

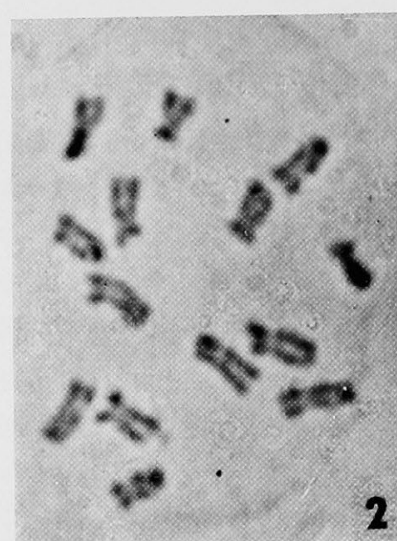

2

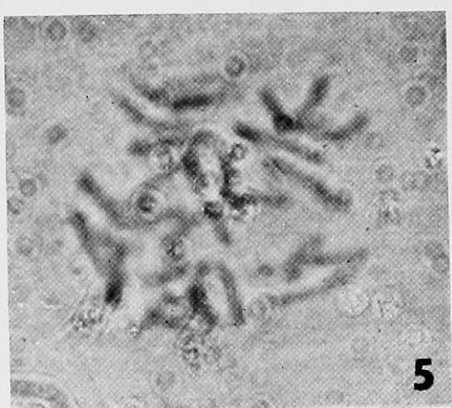

5
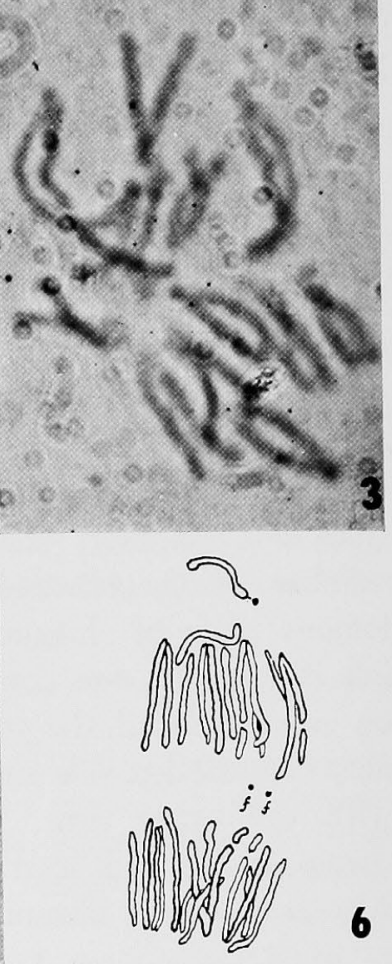

6
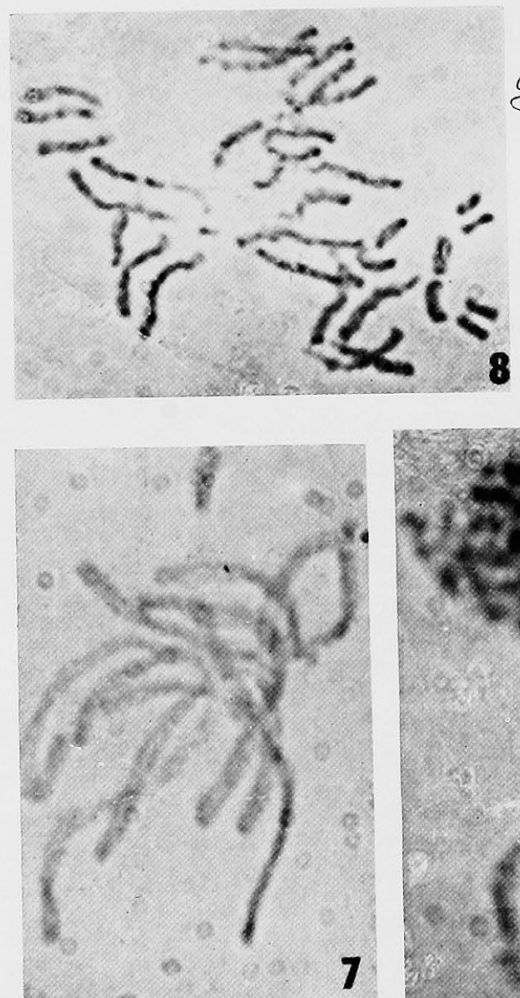

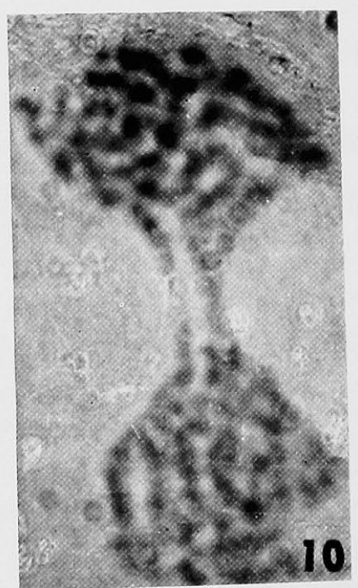


past, only few of them are really worthy of their mentions. Ford (1948), Loveless and Revell (1949), McLeish (1952), Oehlkers (1952), Wilson (1960) and Sharma and Sharma (1960) have made significant contributions on this aspect. As is apparent from the literature that is available the potentialities of this line of investigation are immense. Most of these chemicals inhibit germination and growth, block the mitosis to some extent and produce initial phenomena of a colchicine effect : destruction of the spindle, with the resultant interruption of anaphases and accumulation of metaphases in which the chromosomes shorten, thicken and split but the centromere division is delayed. These interrupted mitoses form tetraploid nuclei, or binucleate cells in some of which there is a bridge between the nuclei. Revelation of spiral structure of the chromosomes and chromosome breakage are some of the other outstanding effects of these chemicals.

During the present investigations concerted efforts were made to bring out the detailed effects of PDB, a very potential and cheap chemical. In all the three genera on which the effect of PDB was noted, $4 \frac{1}{2}$ hours was found to bring about maximum number of anomalies. The precocious separation of the chromatids was encountered in almost all the genera. Carey and McDonough (1943) working with Allium obtained polyploid numbers during the metaphase stages. Lagging chromosomes and dumb-bell shaped nuclei were also occasionally observed by them. These dumb-bell shaped nuclei or two nuclei joined together by one or more bridges were one of the most common anomalies found during the present studies. Such somatic chromosome bridges were also observed by Kodani (1948) and Swaminathan and Natarajan (1956) in Allium and Triticum monococcum respectively.

The cells with tetraploid nuclei showed an effect very similar to that produced by colchicine treatment where it has become conventional to refer to a metaphase resulting from colchicine treatment as a $\mathrm{C}$-metaphase and to use such terms as c-mitoses and c-treatment wherein the " $\mathrm{C}$ " obviously stands for colchicine. Since paradichlorobenzene has been found to be equally effective in producing similar abnormalities in the present work, terms like PDB-metaphase, PDB-mitoses and PDB-treatment are suggested as corresponding terms for convenient use.

As regards the property of chromosome breakage, it may be pointed

Figs. 1-12. Mitotic abnormalities in different species. 1, shortening of chromosomes. Metaphase Vicia faba. 2, precocious separation of chromatids. Metaphase V. narbonensis. 3 , precocious separation of chromatids. Metaphase $V . f a b a .4$, precocious separation of chromatids. Metaphase Lathyrus satious. 5, complete separation of chromatids. Metaphase Pisum arvense. 6, two fragments (f) lying at the centre. Anaphase V. faba (Fig. outlined with India ink and then bleached). 7, separation of large chromatic knob. Prometaphase V. faba. 8, chromosome breakage. Metaphase V. fava. 9, same Fig. outlined with ink, bleached and inked to show reconstruction of two longest pairs of chromosomes. 10, chromosome bridge. Telophase $V$. faba. 11, failure of cell plate formation. Telophase $V$. hirsuta. 12, spiral structural of chromosomes. Prometaphase V. faba. 
out that the chemical is not much toxic to the plant even though it can cause fragmentation to a high degree. Sharma and Bhattacharya (1956) effected chromosome breakage through PDB-treatment in large number of Dicotyledons and Monocotyledons. They came across several cases of chromosome fragmentation. It was revealed that the cells with fragments were noted in the dividing condition even after 96 hours of recovery in Knop's culture solution and the fragments could persist through several cell generations.

The persistence of fragment containing cells following the treatment may be taken as an indication of the potentiality of PDB in mutagenic action. The present observations indicate that the secondary constriction in Vicia faba is a very weak point. The very looseness of association of the large chromatic knob to parent chromosome in this species appears to be one of the factors for the specific breakage at this place. Ford (1948) studied the effect of $\mathrm{NN}$-dimethylene on $V$. faba and proposed that the breaks did not take place at random but rather showed some specificity for heterochromatin. This hypothesis was based on the distribution of breaks within the chromosome compliment and is well supported by the present investigations. Loveless and Revell (1949) and Oehlkers (1952), also confirm the non-randomness of the chromosome breaks. Kihlman and Levan (1951) found apparent localization of the chromosome breaks in the attachment thread of the satellite of the long chromosomes of $V$. faba. The author came across a rare case where the breakage was not only localized to the secondary constriction but was also noticed at the centromere region. Whether the breaks take place at primary or secondary constriction or both, it is quite evident that they are mostly associated with the heterochromatic chromosome regions. In one or two exceptional cases chromosome breakage did take place at the euchromatic regions.

\section{Summary}

Effect of paradichlorobenzene on somatic chromosomes of Vicia faba, $V$. narbonensis, $V$. hirsuta, Pisum arvense and Lathyrus sativus was studied after giving a prolonged treatment. Various mitotic anomalies were encountered. These included shortening and thickening of chromosomes, precocious separation of chromatids, tetraploid cells, binucleate cells, chromosome bridges and chromosome breakage. The potentiality of PDB as a mutagenic substance had been emphasised and terms like PDB-treatment, PDB-mitosis and PDB-metaphase were suggested for convenient use. Chromosome breaks generally took place at the heterochromatic regions.

\section{Acknowledgments}

I am extremely thankful to Dr. S. P. Naithani for able guidance and to Dr. A. K. Sharma for very kindly going through the manuscript. I also 
wish to express my deep sense of gratitude to Dr. Askell Löve and Dr. K. S. Bilgrami for helping me in many ways.

\section{Literature cited}

Carey, M. A. and McDonough, E. S. 1943. On the production of polyploidy in Allium with paradichlorobenzene. Jour. Hered. 34: 238-240.

Ford, C. E. 1948. Chromosome breakage in nitrogen mustard treated Vicia faba. Proc. 8th Int. Congr. Genet. 8: 570-571.

Kihlman, B. and Levan, A. 1951. Localized chromosome breakage in Vicia faba. Hereditas 37: $382-388$.

Kodani, M. 1948. Induction of morphological changes in the chromosomes and of abnormalities in mitotic divisions in the root meristem. Jour. Hered. 39: 327-335.

Loveless, A. and Revell, S. 1949. New evidence on the mode of action of mitotic poisons. Nature 164: 938-955.

Mc Leish, J. 1952. The action of maleic hydrazide on Vicia. Heredity 6 (Suppl.): 125-147.

Oehlkers, F. 1952. Chromosome breaks induced by Chemicals. Heredity 6 (Suppl.): 95-105.

Sharma, A. K. and Bhattacharya, N. K. 1956. Chromosome breakage through paradichlorobenzene treatment. Cytologia 21 (4): 353-360

- and Sharma, A. 1960. Spontaneous and chemically induced chromosome breaks. Int. Rev. Cytol. 10: 101-136.

Srivastava, L. M. 1959. D. Phil. Thesis, University of Allahabad, Allahabad.

Swaminathan, M. S. and Natarajan, A. T. 1956. Chromosome breakage induced by vegetable oils and edible fats. Current Sci. 25: 382-384.

Wilson, G. B. 1960. The study of drug effects at the cytological level. Int. Rev. Cytol. 9: 293-304. 